Article

\title{
Prescribed Reading: Reflective Medical Narratives and the Rise of the Medimoir: An Interview with Adam Kay
}

\author{
Katy Shaw \\ Department of Humanities, Northumbria University, Newcastle Upon Tyne NE1 8ST, UK; \\ katy3.shaw@northumbria.ac.uk
}

Received: 19 November 2018; Accepted: 5 December 2018; Published: 7 December 2018

\begin{abstract}
The 21st century has witnessed the rise of a genre of literature that has taken both the reading public and the publishing industry by storm. The 'medimoir' - or medical memoir-is not in itself a new genre of writing, but has risen to prominence in a contemporary British context of renewed focus on public health and wellbeing, a proliferation of professional confessionals in publishing, and debates about the future of the free-at-point-of-care British National Health Service (NHS). The most prolific medimoir published to date is Adam Kay's This Is Going to Hurt (2017), a reflective diary that chronicles his time as a trainee gynaecologist in the NHS, and his subsequent exit from medical training in the face of growing personal and political pressures on his profession. This article contextualises and considers the rise of the medimoir, and examines why this genre of medical narrative has become such a critical, literary, and publishing success in the first two decades of the new millennium.
\end{abstract}

Keywords: medimoir; narrative; genre; medical; publishing; television; writing; reflective

\section{A Matter of Life and Death}

The idea of a medical professional publishing a book based on their diaries chronicling life on the front line of delivering healthcare services to the general public is not a new one. The medical field has an established tradition of doctors writing down their thoughts on difficult cases, or challenging situations experienced in the workplace as the basis for subsequent discussion with their consultants or educators. The medical training process also has a strong history of reflective writing as a core part of encouraging practitioners to reflect on, and therefore to learn from, successes as well as mistakes, and to share good practice with colleagues. Central to the medimoir as a genre is its grounding in this professional medical culture of reflective practice and reflective writing. Reflection is a key component of becoming an effective practitioner in many skilled industries. As Dewey (1933) outlined, a person who fails to exercise adequate critical reflection runs the risk of making hasty conclusions without examining all possible outcomes. In the 20th century, Boud, Keogh, and Walker updated this definition, framing reflection as 'a term for those intellectual and affective activities in which individuals engage to explore their experiences in order to lead to new understandings and appreciation' (Boud et al. 1985). Their research focuses on experiential learning through reflection and centres on the significance of understanding as a process, rather than a definite end-point, a narrative that evolves over time, rather than finishing with an end-stop. Boyd and Fale also echo this perspective, centring their own discussions on the role of reflection in the act of writing that 'creates and clarifies meaning in terms of self, and which results in a changed conceptual perspective' (Boyd and Fales 1983).

Medical professionals regularly reflect in order to turn their experiences into learning opportunities. The word 'reflect' comes from the Latin word 'reflectere', which means 'to bend back' (Collins 2001) and 
it is this act of return, of quiet thought or contemplation on that which has already passed, and that encourages us to evaluate our own reactions, decisions, and ultimately our own performance as a practitioner. Reflection is a key component of how practice is experienced and how professional skills such as critical thinking and independent judgement are acquired by medical professionals. Since these skills are 'life skills', not just work skills, and reflection can therefore extend into both personal and professional development, making medical staff more aware of their observations and motivations in and outside of the work place. The act of reflecting is predicated on the construction of a narrative through which meaning about past experience or encounters can be understood. Through structured reflection-crafting a story about an experience, learning from it, and enacting change as a consequence-writing becomes an agent for change. Today, reflective writing remains a compulsory requirement of medical training in the UK. The NHS requires all doctors, both in-training and post-qualification, to keep a portfolio of reflective writing based on their practice in an attempt to encourage the enhancement of patient care, but reflective practice also has the potential to encourage the avoidance of personal stress, job dissatisfaction, and burnout. Encouraging doctors to take the opportunity to identify issues swiftly, reflect on them in a supported environment, and action change within their workplace, the reflective writing demanded by medical training portfolios of work in Britain foregrounds this human element of reflective practice.

At the turn of the early 20th century, the reflective writings of medical staff began to gain an audience beyond the realms of solely professional readerships. A Young Doctor's Notebook by Mikhail Bulgakov (2012) became one of the first medical memories to weave fact and fiction in a form that was palatable and intelligible for a popular audience. Best known for his masterpiece, The Master and Margarita, Bulgakov originally wrote short stories with medical themes (including intriguing titles such as "Morphine" and tales of contemporaneous public health fears such as syphilis in "The Speckled Rash") during his time as a graduate doctor, between 1916 and 1918. The text was published in 1963 to widespread acclaim, and subsequent decades saw the publication of a number of other medically-themed short stories by physician-authors including William Carlos Williams' (1984) “The Use of Force", Selzer's (1998) "Brute", Anna Bek's (2004) The Life of a Russian Woman Doctor: A Siberian Memoir and Anton Chekhov's (2008) "Ward No. 6". Since then, there has been a steady stream of reflective writings about life as a medical professional published for popular audiences. The genre has recently reached a new peak of public interest with a post-millennial 'swell of medical memoirs' being commissioned by the contemporary publishing industry (Case 2018). Because medical practice is reflective in nature, the sense of urgency and timeliness in publishing medical narratives today is perhaps not surprising since, in the UK, medics have experienced tumultuous period of political and professional change over the past 10 years that have exposed their profession and working environment to an increasing public spotlight.

\section{Millennial Contexts}

An influential factor in the contemporary rise of the medimoir lies in the satirical approach the genre takes to official discourses concerning the NHS, government, and wider British society. In the wake of the British government's decade-long project of austerity, NHS health services were exposed to a range of government targets and strategic reorganisation that left many services reduced to deficits in terms of both budgets and staffing. The UK government's austerity programme was a fiscal policy adopted in the early years of the 21st century in response to the economic conditions produced by the 2007-2008 global financial crisis. The programme established a deficit reduction target that would be met through sustained public services cuts, reductions to the role of the welfare state, and rises in the amount of taxes paid by members of the public. A cap was placed on public sector pay, and although NHS funding was protected, the resulting impact on social care and services of extensive funding cuts meant that the health service and its staff came under increasing pressure to deliver more services with fewer human and financial resources. 
In this context, the government began to renegotiate contracts for its junior doctors and proposed changes that would abolish overtime rates for work between 7:00 a.m. and 10:00 p.m. on every day except Sunday, while increasing basic pay. The British Medical Association (BMA), countered that in real terms the new contract meant a $40 \%$ reduction in pay for medics, along with extensive preconditions that were not acceptable to its members. The BMA balloted members in November 2015 and industrial action was scheduled for the following month. The initial action was suspended, although further talks broke down. Junior doctors took part in a general strike across the NHS in England on 12 January 2016, the first such industrial action in 40 years. Junior doctors again withdrew their labour for routine care on 10 February, and on 26 April 2016 junior doctors totally withdrew from emergency and routine care, the first time this had happened. Despite their action, the new government contracts were advanced, leading many younger members of the profession to leave for jobs in America and Australia, and those remaining to face carrying on in the same profession for less money, poorer conditions, and worse overall prospects.

This sustained period of struggle at both national and local levels had a significant impact on the experiences of those medical staff, and on general public awareness of the growing challenges facing the NHS. Out of this context came a series of new texts that sought to reflect life on the front line of the NHS in the 21st century. In the wake of this dispute, new cultural representations of medical narratives and the rise of the medimoir offered their authors potent right of reply in face of a homogenising media discourse about medical staff. On the small screen, these crises were widely represented in television dramas, documentaries, and live shows exposing the reality of life on the front line of over-stretched NHS services. From fictional representations such as Casualty (BBC 1986-present) and Holby City (BBC 1999-present) to fly-on-the-wall shows including GPs Behind Closed Doors (Channel 5 2014-present) and Junior Doctors: Your Life in Their Hands (BBC Three 2011-2013) to NHS Live (ITV 2018) - a three night series broadcast live from the busiest accident and emergency department in the UK-during the second decade of the new millennium the professional environments and challenges of medical staff were exposed to the pubic gaze like never before.

This new trend for medical programming was accompanied by a new trend in print publishing for anonymous tell-all-tales about life behind the scenes of some of British society's most highly-regarded occupations. Understood as part of this wider confessional narrative culture-from I Am the Secret Footballer (2012), to The Secret Teacher: Dispatches from the Classroom (Anon 2017) , and The Secret Barrister: Stories of the Law and How Its Broken (Anon 2018) - the medimoir tapped into a hunger in contemporary readers for uncensored glimpses of life on the front line of public services. Fuelled by an increased desire for insight into revered yet little understood professions, and a degree of empathy with public servants like medics who survive for the love of the job, these new cultural representations of medical narratives offered the general public with an education about the value of reflective practice to the medical ability and mental well-being of medical staff, and a warning of the time bomb of the tired army of medics underpinning the NHS.

\section{This Is Going to Hurt}

From 2010 onwards in the UK and US, there was a notable surge in the number of new medimoirs being commissioned and published. From supermarkets to bookstore window displays, the medimoir rose to generic prominence across this period through a range of key titles including Trust Me, I'm a (Junior) Doctor by Max Pemberton (2011), Your Life in My Hands by Rachel Clarke (2017), Admissions: A Life in Brain Surgery by Henry Marsh (2018), and The Language of Kindness: A Nurse's Story by Christie Watson (2018). These medimoirs offer necessarily individual narratives, but each also draws upon and helps to underscore a wider sense of shared experience and solidarity across the NHS workforce. Indeed, these medimoirs are perhaps most notable for their graphic detail about the contemporary NHS, and for their use of dark humour when tackling matters of life and death. Born from a contemporary context in which critical clinical decisions are made in a single second, after almost as little sleep, medimoirs also detail frequent cases of sexism, racism, and workplace bullying are numerous, but so 
are random acts of kindness by colleagues and patients, and a blitz spirit in the face of staff shortages and resultant rota gaps pervades.

Absorbing and relentless as the job they occupy, these 24-7 accounts offer an insider perspective on what happens behind the curtains and doors of medical wards, and how this can seep out to impact to lives and psyche of staff once they have clocked off their shifts. Giving a human voice to individuals working in an increasingly depersonalised and mystifying system of care that appears to be in a perpetual state of crisis, 21st century medimoirs shared a similar structure-exposition, complication(s), resolution-but that resolution often means a major change resulting from this process of narrative reflection. In many medimoirs, that resolution often takes the form of an exit from a specific specialism, the medical field altogether, or even intro retirement. Part biography, part diary, part bildungsroman, these factional and educational medical narratives are also inherently political. By choosing to profile otherwise invisible experiences, and to exercise unheard voices, the authors of medimoirs offer radical reflective writings and declare their own identity to underscore the personal testimony of their stories.

Despite the collective success of these titles, the most commercially and critically prolific contemporary medimoir, and a text that has come to define debates about the genre in the 21st century, is Adam Kay's 2017 This Is Going to Hurt, a medimoir based on diaries written between 2005 and 2010 when Kay worked as a junior doctor specialising in obstetrics and gynaecology. He had previously performed a drama based on the same medical diaries as a one-man show at the Edinburgh Festival in 2016, but following that year's junior doctors' strike and the wider growth of the medimoirs in the publishing marketplace, the medic-turned-screenwriter was commissioned by publishers Picador to turn his writings into a book. Alan Staton, head of marketing and communications at the Booksellers Association, which runs the British Book Awards, argues that the success of Kay's medimoirs has to be understood in the context of a wider shift in public appetite for medical narratives. At the time of Kay's award win in 2017, Staton reflected that "Adam Kay's is very much the same this year, igniting conversations [about the NHS], and so it is no surprise it has won" (quoted in Kean 2017). The medimoir went on to sell over a million copies internationally, was The Sunday Times Number One Bestseller, Humour Book of the Year Winner, winner of the Books Are My Bag Book of the Year, Winner of iBooks' Book of the Year, winner of Blackwell's Debut of the Year (2017), winner of the British Book Awards: Best Non-Fiction Book 2017, and came top in a poll of readers to win the Books Are My Bag readers' choice voted for by 40,000 members of the public through bookshops. The publishing success of This Is Going to Hurt generated a return of the live stage that now sees its author touring theatres in a stage performance based on his medimoir. In 2018, Kay's book was also optioned for a $\mathrm{BBC}$ television series, and for a film.

Like many other texts in its genre, Kay's medimoirs exposes a clear tension between public demands for medical staff to 'be more human', as set against a medical system that treats the same staff inhumanely. Across medimoirs, authors detail numerous instances of denied sick leave, enforced overtime and, resultantly, a fundamentally damaged personal life. A lunch or toilet break are rare occurrences in these texts, and as a consequence, readers are encouraged to empathise with medical staff and consider them as fallible and human individuals, often under-paid and over worked, and enduring lengthy training periods that demand they relocate across UK to complete their studies. Kay's medimoir does not shy away from detailing the uncomfortable reality of working as a doctor in the NHS today, as 97-h weeks and sleepless nights become increasingly hard to tolerate when he works out that the hospital parking meter is actually earning more than he is as a junior doctor. Kay claims he was conscious of the genre's approach to presenting the human side of medical life while writing his own medimoirs. As a result, he opted to construct his narrator as a "low-grade superhero" in order to remind readers that "a doctor is someone with a flat and a partner and a life", just like everyone else (quoted in Hawksley 2017). 


\section{In Conversation: Adam Kay}

I spoke with Adam Kay in London, England during September 2018. During our interview, we talked about the rise of the medimoir, his own experience of reflective writing, and his reflections on publishing the most commercially and critically successful medical narrative to date. In the middle of his national tour promoting the book just over a year since its original publication, Kay offered some thoughts on the informing role of context in genre fiction, and the future of the medimoir as a popular form of medical narrative.

The medimoir has a long history in Western literature, but began to rise in popularity across the last decade. Had you read any other Medimoirs before writing your own?

I'd been bought them all as gifts, but I'd never thought that I'd be writing a book. In fact, when I agreed to turn my diaries into a book I deliberately made sure I didn't read any other medimoirs around that time because I didn't want to become a shit tribute act. I was aware of the genre but I wasn't obsessed with it! I had read others in the genre, basically as a doctor I had read the best-sellers that were about doctors.

Did your experience of performing in a sketch group at university help you approach the task of writing your medimoir?

In retrospect, performing drama was a coping mechanism, just like writing the diaries, in lieu of a proper coping mechanism. I was a creative always trying to escape, but I was steered towards a sensible living. I did enjoy writing at school but I did edit the school magazine, and wrote for the medical review at university. While I was doing that a television doctor saw me doing stuff at a medical revue and I wasn't good but I was medium in a terrible show, so I ended up writing a bit for his radio show while I was at university, so I had done little bits. But being a doctor doesn't allow for an enormous amount of hobby-time, so the diaries gave me that writing time but in the context of also doing my job.

\section{Reflective writing is a key part of training to be a medic-how useful was that practice of keeping a portfolio of your thoughts during training?}

I'm not a huge reader. Most people only read three or four books a year and I was one of those. The idea of writing a book seemed so far from my world, but after talking to an agent I felt confident enough to I'm not sure I would have been so honest if I thought anyone would ever read it. When they say to you as a doctor-you have to write down and keep records of stuff-that morphed into my natural desire to write, plus it offered me some shards of light in those tougher times. I turned writing into my coping mechanism. I think there are more basic problems with caring for the carers, and as a way of addressing that medical reflective writing should be supported and actioned in a better way. It's part of the same underlying cultural issue that most reflective writing feels like it doesn't really reach an audience, whereas stats on the number of operations you've done are regarded much more highly. I wrote it confidentially as it was just for myself-I knew no one else was ever going to read it!

\section{How did the context of recent events in the NHS inform the way you approached your medimoir?}

I had been thinking what I could do to support the junior doctor strike action. All I had was this repository of stories that I'd been using to upset guests at dinner parties, and I read out the funny entries as the basis of the stage show, I didn't talk about the ending of the diaries. I wasn't ready at that stage. I thought I could just say the stuff about moving hospitals, the stuff about its impact on your life, but people didn't think it went anywhere in terms of a conclusion. People said it was funny, but it didn't explain why I was standing up on stage and wasn't working on a labour ward. The truth was I never spoke about that, and the first time I read it out on stage was the first time that anyone who wasn't working at that hospital at the time had heard about it. It was the first time my family found out what happened was reading it in the book. Because there's a culture that says you don't talk 
about these things. Today, it's so easy to get in touch with an author, and since the book came out I get so many messages from doctors saying 'I've never told anyone this but ... ', and then telling me these awful things. Because doctors aren't meant to open up. The public weren't told both sides of the argument in the junior doctor dispute, they had predominantly one-sided data. I wasn't wanting to tell people what to think, just to profile that there was another side to the argument, and that telling my story would enhance awareness and amplify that perspective across the general public. One of the things I like about the reaction to the book is from doctors saying this is the book I can give to friends and family and they can learn how it really is. I don't think many books in the past have majored on the impact of being a doctor on being a human being, particular in your home life.

Given the weighty and complicated subject matter of the medimoir, how important was it to profile the role of humour?

I didn't want the show to end on that story, but by adding it to the end of the show.

If I'd called the book A Harrowing Polemic about the NHS it wouldn't have sold as many copies. We made it look like a funny book with the puff quotes and the cover design, Picador were really collaborative. It was going to be called Your Life in My Hands, but another medimoir-Rachel Clarke-had just announced that she was publishing a book a few months earlier with that exact same title. So we had to come up with a new title. The book was put together so quickly.

This Is Going to Hurt has recently been optioned for a television drama series with the BBC, and a film. What are the challenges of adapting a medimoir into a different form?

If we just filmed the book it would be a sketch show, and we took it to the drama department for that reason, medicine is inherently about the drama, and we want the TV show to reflect that. It's much more of a collaborative writing process than the book, and if anyone watches it (!) hopefully that will further amplify the medic's voice and perspective. The book has sold more copies than most TV shows have viewers, so in terms of awareness and impact its key to try to reach as many audiences as possible. I wrote it to be read, I suspected it wouldn't be beyond a fairly limited circle, but it has, and I want that to continue as much as it can. The book is about a public service, and I hope it does a public service in terms of awareness raising and engaging people in alternative perspectives on debates.

\section{Prescribed Reading}

Centring a narrative on the medical experiences of practitioners as well as patients, the medimoir profiles human conditions and the everyday, rather than extraordinary, challenges which offer inspiration and illumination to readers. Across contemporary examples of the medimoir genre, shock and memorable instances are generated not by their author's salacious use of hyperbole but in their normalised responses to the extraordinary scenarios they encounter on a daily basis as part of their professional engagements with the general public. As Jeeves Wijesuriya, chair of the British Medical Association's junior doctors committee, has publicly argued that the genre of the medimoir has a profound professional and social function for today's medics, thanks to its "painting in dark, tongue-in-cheek humour the peculiarities and heartbreaks of life as junior doctor, the vibrancy, humour and tragedy of hospital life and the personal impact of sharing these intensely personal moments" (quoted in Silver 2017).

Through their use of the medimoir genre, a new generation of medics have shown how it is possible to mobilise reflective writing to dispense humour, empathy and understanding of the lived consequences of government austerity and wider shifts occurring in a national healthcare system, and to create a new form of medical narrative for the new millennium. This Is Going to Hurt has arguably become the most critically and commercially successful example of the genre to date precisely because it strikes this balance between political, social, and personal approaches to medicine.

Like its post-millennial medimoir contemporaries, This Is Going to Hurt has made visible the day-to-day life of medical professionals and offered important new medical narratives to the reading 
public. Exposing the 'secret' reality of medical life, the medimoir offers a new genre of narrative with vital revelations and reflections for the 21st century world. Its rise in the contemporary period is bound up so closely with the tumultuous political and economic conditions of post-crash society that imbue these texts with an agency far beyond the professional remits of the reflections on practice that they capture. In turning the inherently inward-looking focus of the first person, the memoir, and reflective writing outwards to a wider readership, and amplifying the silent struggles of medical staff and their patients, the medimoir underscores the vital role of medical narrative in enhancing public and professional understanding of the challenges, and opportunities, facing healthcare professionals today.

Funding: This research received no external funding.

Acknowledgments: The author would like to extend special thanks to Adam Kay and to Northumbria University for supporting the work.

Conflicts of Interest: The author declares no conflict of interest.

\section{References}

Anon. 2017. The Secret Teacher: Dispatches from the Classroom. London: Guardian Books.

Anon. 2018. The Secret Barrister: Stories of the Law and How It's Broken. London: Pan Macmillan.

Bek, Anna. 2004. The Life of a Russian Woman Doctor: A Siberian Memoir. New York: Indiana University Press.

Boud, David, Rosemary Keogh, and David Walker. 1985. Reflection: Turning Experience into Learning. London: Kogan Page.

Boyd, Evelyn M., and Ann W. Fales. 1983. Reflective Learning: The Key to Learning from Experience. Journal of Humanistic Psychology 23: 99-117. [CrossRef]

Bulgakov, Mikhail. 2012. A Young Doctor's Notebook. London: Alma Classics.

Case, Molly. 2018. The Language of Kindness: A Nurse's Story by Christie Watson-Review. The Guardian, April 29. Available online: https://www.theguardian.com/books/2018/apr/29/language-of-kindnessnurses-story-christie-watson-review (accessed on 27 October 2018).

Chekhov, Anton. 2008. Ward No. 6 and Other Stories, 1892-1895. Oxford: Oxford University Press.

Clarke, Rachel. 2017. Your Life in My Hands. London: Metro.

Collins, Harper. 2001. Collins English Dictionary, 3rd ed. London: Collins.

Dewey, John. 1933. How We Think: A Restatement of the Relation of Reflective Thinking to the Educative Process. Boston: DC Heath.

Hawksley, Rupert. 2017. Hot Wax Was Dripping into His Bladder. The Telegraph, December 5. Available online: https:/ / www.telegraph.co.uk/books/authors/hot-wax-dripping-bladder-former-doctor-adamkay-revolting/ (accessed on 27 October 2018).

Kean, Danuta. 2017. Doctor's Diary This Is Going to Hurt Wins Public Vote for Book of the Year. The Guardian, November 21. Available online: https:/ / www.theguardian.com/books/2017/nov/21/doctors-diary-thisis-going-to-hurt-wins-public-vote-for-book-of-the-year (accessed on 27 October 2018).

Marsh, Henry. 2018. Admissions: A Life in Brain Surgery. New York: Weidenfeld and Nicolson.

Pemberton, Max. 2011. Trust Me, I'm a (Junior) Doctor. London: Hodder \& Stoughton.

Selzer, Richard. 1998. Brute. In The Doctor Stories. New York: Picador USA.

Silver, Laura. 2017. Heard the One about the Doctor and His Diary? Buzzfeed, September 10. Available online: https:/ / www.buzzfeed.com/laurasilver/this-ex-doctor-turned-comedian-wrote-a-memoir-andhes?utm_term=.hk0JL0YxN\#.mhWjkq8pL (accessed on 27 October 2018).

Watson, Christie. 2018. The Language of Kindness: A Nurse's Story. London: Penguin.

Williams, W. C. 1984. The Use of Force. In The Doctor Stories. Edited by Robert Coles. New York: New Directions. 